\title{
ISOLATION, CHARACTERIZATION AND GROWTH CONTROL OF A SULFATE REDUCING BACTERIA FROM SEWAGE WATER
}

\author{
DASH, J. - DAS, T. - MISHRA, B.K. - KAR, R.N. ${ }^{*}$ \\ Institute of Minerals and Materials Technology (CSIR) \\ Bhubaneswar-751012, Orissa, India \\ (phone: 916742581636 Ext.314; fax: 91674 2581637, 2581160) \\ *Corresponding author \\ e-mail: kar_rn2002@yahoo.co.in
}

(Received 29 $9^{\text {th }}$ August 2007; accepted $5^{\text {th }}$ January 2012)

\begin{abstract}
Sulfate Reducing Bacteria (SRB) are a diverse heterogeneous group of anaerobic microorganisms inhabiting in various environmental conditions. SRB are one of the most important groups of microorganisms that participate in various nutritional cycles of the environment and cause degradation of various organic matters through the process of dissimilatory sulfate reduction. They are known to be implicated in cases of microbially influenced corrosion arising in a wide range of natural and industrial circumstances. SRB are known to utilize the indigenous sulfate source and hence produce the deadly poisonous hydrogen sulfide $\left(\mathrm{H}_{2} \mathrm{~S}\right)$ gas. In the present study one strain of SRB designated as WS-1 was collected from sewage water. The sample was enriched in a basal mineral media in an anaerobic condition using lactic acid as carbon source. The isolated strain (WS-1) was Gram negative cocci shaped and occured in chains and pairs. Biochemical characterization of the strains revealed that, the strain WS-1 was closely related to Veillonella. Sulfate reduction and sulfide formation were evident both in case of lactic acid and acetic acid as carbon source. It was observed that sodium nitrate and potassium nitrate were effective in controlling sulfide formation.
\end{abstract}

Keywords: Sulfate Reducing Bacteria, nitrate, sulfide

\section{Introduction}

The Sulfate Reducing Bacteria (SRB) constitutes a morphologically and physiologically diverse anaerobic group of microorganisms. They have the capacity to reduce sulfate present indigenously in the environment and reduce it to deadly poisonous hydrogen sulfide gas.

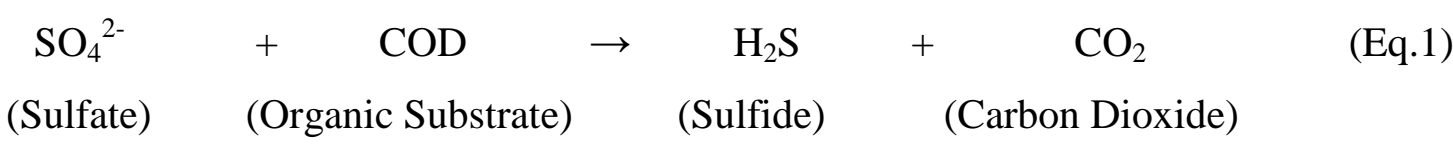

Typically, SRB are found mainly in marine and freshwater sediments where sulfate is present in abundance (Nielsen et al., 1999). But they are also found in agricultural and industrial waste water systems, in oil fields and also in cooling towers (Dan et al., 1996; Postgate, 1984; Rao et al., 2000). These microbial consortia can utilize sulfate, thiosulfate, sulfite and elemental sulfur as electron acceptors but cannot utilize nitrate, nitrite or formate (Azabou et al., 2007). They can also utilize environmental substances such as benzene, toluene, ethylbenzene, xylenes, naphthalene, phenanthrene and alkanes and halogenated compounds (Ensley et al., 1995; Zhang and Young 1997). The bacterial strains are also able to utilize peptone, asparagine, glycine, alanine, aspartic acid, ethanol, propanol, butanol, glycerol, glucose, lactate, succinate and malate .The main disadvantages of these SRB's are that they cause the souring of oil and corrosion 
of pipelines thereby making huge economical loss to oil industries. Hence it lowers the economic value of the produced oil and imposes safety hazards due to $\mathrm{H}_{2} \mathrm{~S}$ toxicity. Therefore, it is important to study the growth and control the activity of SRB.

Previously it was reported that biocides targeting SRB were widely used (Jayaraman et al., 1999) in controlling the growth of SRB in surface facilities but mostly the biocides cannot penetrate bio-films readily within reservoirs or on the metal surfaces of industrial equipment (Gardner and Stewart, 2002). It is also reported (Gardner and Stewart, 2002) that biocide-resistant SRB can often emerge in due course of time due to frequent use of the same.

Several methods for sulfide removals are in common use today. Some of these are physio-chemical process that involves direct air stripping, oxidation and chemical precipitation. The major disadvantages of these conventional systems are the relatively high-energy requirement or the high chemical and disposal costs (Busiman et al., 1989). Therefore the need arises to make an extensive study on biological control of SRB. Nitrate is applied to control the growth of SRB and result in both transient and longterm inhibition of sulfide production (Allen, 1949). Naphthalene is also proved to be an effective controlling agent of SRB. As reported earlier the addition of high concentrations of nitrate can generate nitrous oxide, which increases the redox potential, leading to long-term inhibition of sulfide production (Allen, 1949; Jenneman, 1986). Naphthalene also proved to be toxic for the microorganisms using polycyclic aromatic hydrocarbons as carbon source (Gracia et al., 1998).

Keeping in view the above aspects, the current study deals with purification and characterization of SRB isolated from sewage water sample collected from the campus of Institute of Minerals and Materials Technology, Bhubaneswar during December, 2006. The present investigation deals with hydrogen sulfide production by utilization of various substrates like lactic acid and acetic acid. Another set of experiment deals with whether various nitrate sources as well as naphthalene could be useful for controlling growth of SRB and reducing the production of hydrogen sulfide.

\section{Materials and Methods}

\section{Site description and sampling procedure}

The experiments were carried with sewage water sample. The water sample designated as WS-1 was collected from the sewage canal of Institute of Minerals and Materials Technology, Bhubaneswar, Orissa. Sample collections were performed in December, 2006.

The water sample $(20 \mathrm{~mL})$ was collected in sterile screw capped glass bottle entirely filled and sealed with cap to maintain anoxic condition.

\section{Isolation and cultivation of pure cultures}

Samples were inoculated in enrichment media within $24 \mathrm{~h}$ of sampling. The inoculated sample was incubated at $35^{\circ} \mathrm{C}$ for a period of at least 2 weeks. Growth of the microorganism was analyzed by microscopic study in every 7 days. Pure cultures of the microorganism were obtained by repeated application of streaking in Basal mineral media (3\% agar) supplemented with $\mathrm{K}_{2} \mathrm{HPO}_{4} 0.3 \mathrm{~g} / \mathrm{L}, \mathrm{KH}_{2} \mathrm{PO}_{4} 0.3 \mathrm{~g} / \mathrm{L},\left(\mathrm{NH}_{4}\right)_{2} \mathrm{SO}_{4}$ $0.3 \mathrm{~g} / \mathrm{L}$. The inoculated Petri plates were incubated at $35^{\circ} \mathrm{C}$ in anaerobic chambers in an atmosphere of $\mathrm{CO}_{2}$ which contains less than $1 \%$ oxygen. Anaerogen sachets were also provided in the anaerobic chamber. After an incubation period of 1-2 weeks well 
isolated colonies were observed in the plates. Purity of isolated strains was checked by direct microscopic observation in leica phase microscope.

The basal mineral media used for cultivation and isolation of SRB contained in g. $\mathrm{L}^{-1}$ : $\left(\mathrm{NH}_{4}\right)_{2} \mathrm{SO}_{4}-3, \mathrm{MgSO}_{4^{-}}$1.5, $\mathrm{NH}_{4} \mathrm{Cl}-1, \mathrm{~K}_{2} \mathrm{HPO}_{4}-0.65, \mathrm{CaCl}_{2} .2 \mathrm{H}_{2} \mathrm{O}-0.08, \mathrm{FeNH}_{4} \mathrm{SO}_{4,-}$ $0.01 \mathrm{CH}_{3} \mathrm{CHOHCOOH} / \mathrm{CH}_{3} \mathrm{COOH}-5 \mathrm{~mL}$, Yeast Extract-0.2, Trace Elements- $1.5 \mathrm{~mL}$, Riboflavin-2mL, Resazurin-0.002g. Resazurin was added as a redox indicator. The $\mathrm{pH}$ of the medium was adjusted to 7.5-7.8 with $1 \mathrm{~N} \mathrm{NaOH}$. The constituents of trace element solution used in mineral media contained in $\mathrm{g} / \mathrm{L}: \mathrm{MnCl}_{2}-1, \mathrm{CoCl}_{2}-1, \mathrm{NiCl}_{2}-0.2$, $\mathrm{CuSO}_{4}-0.1, \mathrm{ZnSO}_{4}-0.1$ and $\mathrm{H}_{3} \mathrm{BO}_{3}-0.1$. Isolation was done in specially designed gas passing bottles. The bottles were supplemented with $1 \mathrm{~mL}$ water sample respectively and fluxed with nitrogen and $\mathrm{CO}_{2}$ gases to maintain anaerobic condition.

\section{Morphological, physiological and biochemical characterization}

A Leica phase microscope was used to observe the Gram staining as well as cell shape and motility. The physiological characterization of the isolated SRB strain (WS1) was studied according to the ability to grow in basal mineral media for a period of two weeks. To determine the ability of the SRB to utilize various carbon sources, isolated bacteria were grown in basal mineral media replacing lactic acid with acetic acid. The media turned black which indicates the positive result. For biochemical characterization, media were used supplied by HI media. The isolated strains were inoculated in the freshly prepared sterilized media and incubated at $35{ }^{\circ} \mathrm{C}$ inside the anaerobic chambers which was vacuumed and subsequently fluxed with $\mathrm{CO}_{2}$ gas.

\section{Analytical techniques}

Amount of sulfide was analyzed by titrometric method using $0.1 \mathrm{~N}$ sodium thiosulfate as titrant and starch as indicator with $10 \mathrm{ml}$ of sample solution [Vogel, 1961].

Table 1. Colony Morphology of the strain WS-1

\begin{tabular}{c|c|c|c|c|c|c|c}
\hline $\begin{array}{c}\text { Agar } \\
\text { medium } \\
\text { used for } \\
\text { isolation }\end{array}$ & Colour & Form & Elevation & Margin & Size(mm) & Surface & Structure \\
\hline $\begin{array}{c}\text { Basal } \\
\text { Mineral } \\
\text { Media } \\
\text { fortified } \\
\text { with agar }\end{array}$ & Pinkish & $\begin{array}{c}\text { Small, } \\
\text { circular }\end{array}$ & Irregular & Entire & $0.5-2$ & Glistening & Opaque \\
\hline
\end{tabular}

\section{Results and Discussion}

\section{Isolation}

It was observed that the colour of the fresh media first turned blue then to colourless and lastly colour changed to pink after 2-3 days of incubation. Then finally the media turned to deep black colour with black precipitate at the bottom of the culture vessel after two weeks of incubation at $35^{\circ} \mathrm{C}$. This indicates the formation of hydrogen sulfide due to the degradation of the carbon source. The sample (WS-1) was taken in duplicates. In one set of sample Nitrogen gas was fluxed and in the other set Nitrogen gas was not supplied instead the bottles were stoppered after filling the culture vessels fully with media. Sulfate accumulated concomittantly with hydrogen sulfide. Cultures 
having the highest dilution with growth $\left(10^{5}\right)$ cells $/ \mathrm{mL}$ were used for further isolation studies. It was interesting to note that microscopic examination revealed one major bacterial morphotype that occurred predominantly having colony morphology given in (Table 1). The type was coccoid and non-motile. Purification of the culture was done by single colony isolation method on basal mineral media fortified with agar and a single colony was taken for biochemical characterization study.

Table 2. Biochemical Tests

\begin{tabular}{|c|c|}
\hline NAME OF BIOCHEMICAL TESTS & WS-1 \\
\hline INDOLE & - \\
\hline MR & - \\
\hline VP & - \\
\hline CITRATE UTILIZATION & _ \\
\hline LYSINE DECARBOXYLASE & + \\
\hline ORNITHINE DECARBOXYLASE & + \\
\hline UREASE & - \\
\hline CATALASE & + \\
\hline PHENYLALANINE DEAMINATION & _- \\
\hline GLUCOSE & + \\
\hline ADONITOL & + \\
\hline ARABINOSE & + \\
\hline LACTOSE & + \\
\hline SORBITOL & + \\
\hline MANNITOL & + \\
\hline RHAMNOSE & + \\
\hline SUCROSE & + \\
\hline OXIDASE & + \\
\hline $\begin{array}{c}\text { Identified as } \\
\text { (Maximum resemblance with) }\end{array}$ & Veillonella \\
\hline
\end{tabular}

\section{Characterization}

Cells of strain WS-1 was found to be Gram negative cocci shaped occurring in short chains as seen under higher magnification. These strains were found to be positive for lysine decarboxylase, ornithine decarboxylase, oxidase, catalase and also for all the carbohydrate utilisation as shown in (Table 2). The colony morphology is shown in (Table 1). From the characterization study the isolated strain was observed to be having close similarity with Veionella species (Holt, 1989).

From the protein assay it was observed that the result was in match with the direct microscopic count. In WS-1 sample the growth and activity of the bacteria increased up to 14 days that indicates the log phase of growth of SRB in the particular sample. Subsequently the stationary growth phase of the organism was achieved which was noted with the decline in growth and activity of the bacterial cells. After 28 days of 
incubation, the growth was completely retarded, indicating the initiation of death phase of the microorganisms.

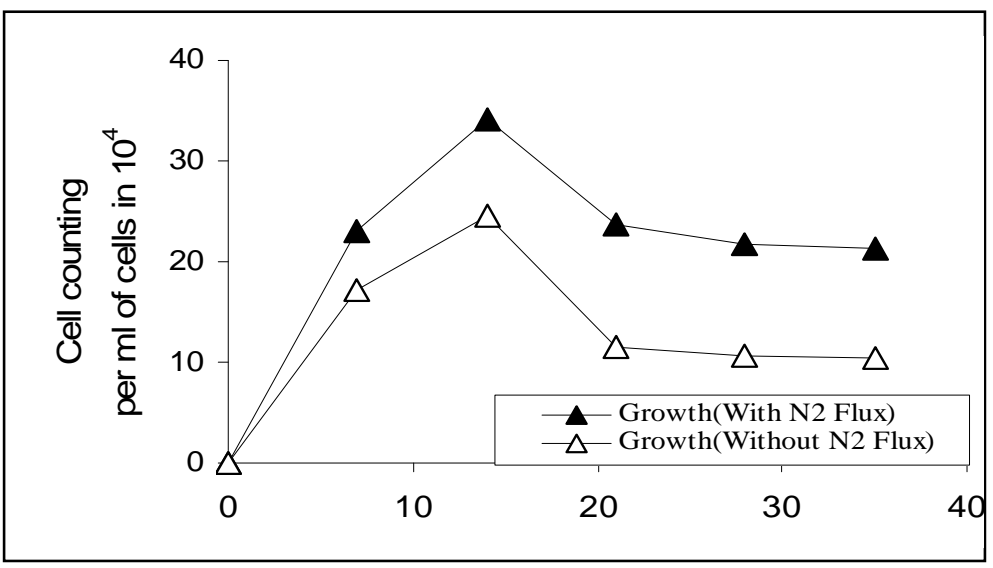

Figure 1. Growth of isolated WS-1 strain of SRB in anaerobic basal mineral media with different conditions of nitrogen flux with lactic acid as substrate

From the above observations it was believed that the bacterial log phase continued till 14 days of incubation. The observations were concordant with the increase in bacterial cell count which increased up to $10^{5}$ cells $/ \mathrm{mL}$ during this period. This fact was further justified when the results of the protein assay increased up to 14 days and then a decline was observed in the amount (Fig.7). Same result was also observed in case of carbohydrate assay, which further supported the fact. The amount of protein obtained was in the range of 0.05 to $0.2 \mathrm{mg} / \mathrm{mL}$ of bacterial culture as shown in (Fig.7) and the amount of carbohydrate was in the range of 0.01 to $0.1 \mathrm{mg} / \mathrm{mL}$ of bacterial culture as shown in (Fig.7).



Figure 2. Growth of isolated WS-1 strain of SRB in anaerobic basal mineral media with different conditions of nitrogen flux with acetic acid as substrate 


\section{Growth studies}

From the growth studies of WS-1 it was observed that there was an increase in the bacterial cell count up to 14 days which was in the range of $10^{4}$ to $10^{5} \mathrm{cells} / \mathrm{ml}$ indicating the log phase of growth of SRB and then stationary phase was achieved. A decline in growth was observed after 28 days indicating the initiation of death phase of cells. The growth results were slightly higher in nitrogen flux samples indicating that by nitrogen flux better anaerobic condition was maintained as shown in (Fig. 1). It was observed that growth was better in case of lactic acid as substrate than with acetic acid as substrate (Fig.2), which implies that lactic acid is a more preferable carbon source for the growth of SRB.

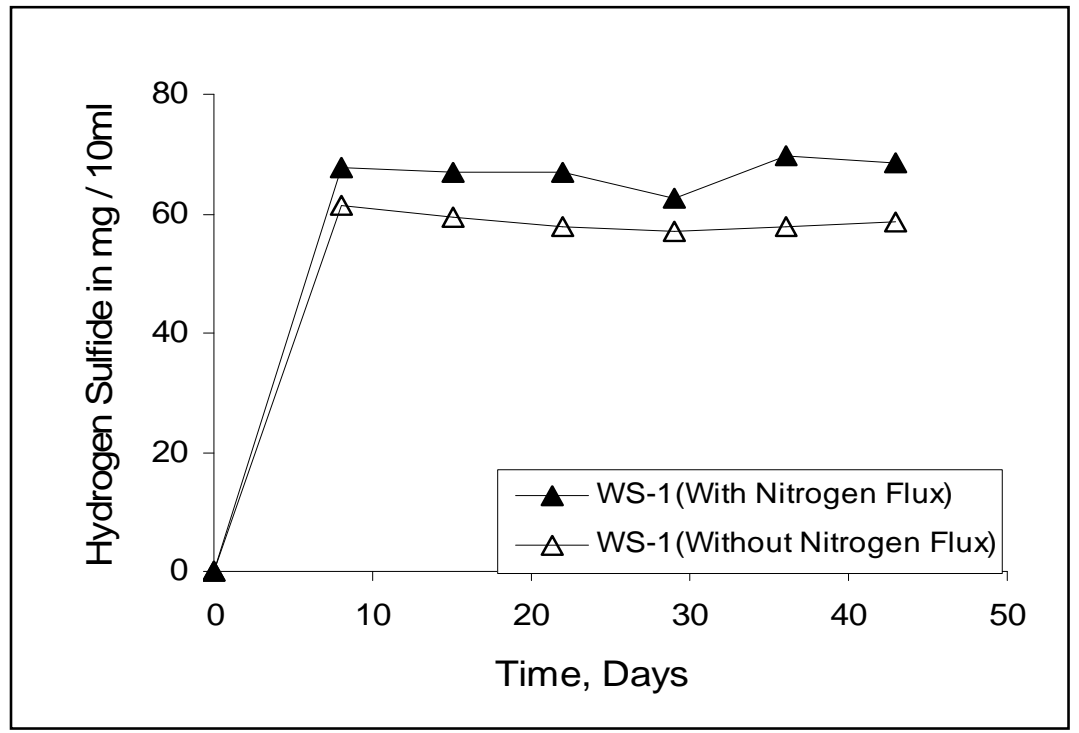

Figure 3. $\mathrm{H}_{2} \mathrm{~S}$ production by the WS-1 strain in anaerobic basal mineral media with different conditions of nitrogen flux with lactic acid as substrate

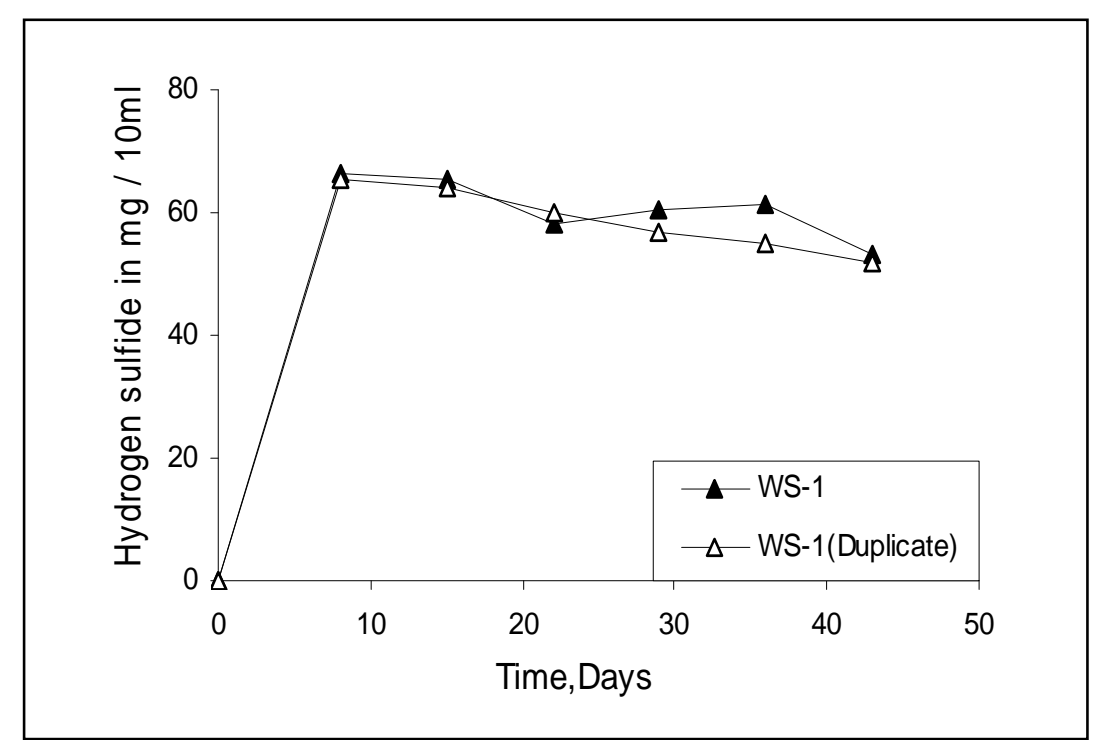

Figure 4. $\mathrm{H}_{2} \mathrm{~S}$ production by the WS-1 strain in anaerobic basal mineral media with different conditions of nitrogen flux with acetic acid as substrate 


\section{Analysis of $\mathrm{H}_{2} \mathrm{~S}$ production with lactic acid as substrate}

The lactate that was used as a carbon source was degraded in the culture medium and the same was associated with sulfate reduction and sulfide production. The $\mathrm{H}_{2} \mathrm{~S}$ production was increased up to 15 days of incubation at $35{ }^{\circ} \mathrm{C}$ and from 22 days to 43 days the $\mathrm{H}_{2} \mathrm{~S}$ production remained the same. From the experiments conducted it was observed out that slightly lower $\mathrm{H}_{2} \mathrm{~S}$ production was seen in the culture medium not fluxed with $\mathrm{N}_{2}$ as compared with $\mathrm{N}_{2}$ flux condition as shown in (Fig.3) supporting the fact that under $\mathrm{N}_{2}$ flux conditions the anaerobic condition is better maintained which helps maintaining the sound growth and activity of the microorganisms.



Figure 5. Effect of sodium nitrate on $\mathrm{H}_{2} \mathrm{~S}$ production by WS-1 strain in anaerobic basal mineral media with different conditions of nitrogen flux with lactic acid as substrate and with acetic acid as substrate

\section{Analysis of $\mathrm{H}_{2} \mathrm{~S}$ production with acetic acid as substrate}

Acetate was degraded slowly as a carbon source, so there was lower $\mathrm{H}_{2} \mathrm{~S}$ production in comparison to the lactic acid as carbon source as shown in (Fig.4). In this experimental set up $\mathrm{N}_{2}$ was fluxed as better results were obtained in case of $\mathrm{N}_{2}$ flux from the previous experiments. Therefore it can be concluded that the isolated strains of SRB utilized lactic acid as a more preferable carbon source than acetic acid.

\section{Effect of sodium nitrate salts on $\mathrm{H}_{2} \mathrm{~S}$ production}

Effect of addition of sodium nitrate to the growth media was studied in order to determine the effect of the same on the $\mathrm{H} 2 \mathrm{~S}$ production. $80 \mathrm{mM}$ of sodium nitrate was added to two bottles. In one bottle Nitrogen gas was fluxed and the other bottle was stoppered after filling the bottle with freshly prepared media. The addition of nitrate consistently diminished sulfate reduction and $\mathrm{H} 2 \mathrm{~S}$ production in both lactic acid and acetic acid as substrate (Fig.5). In the experimental set up with acetic acid as substrate N2 was fluxed as better results were obtained in case of N2 flux than without N2 flux condition. It was observed that the addition of higher concentration $(80 \mathrm{Mm})$ of nitrate 
prevented sulfidogenesis (Fig.5). Nitrate salts decrease the activity of utilization of sulfate source by SRB.

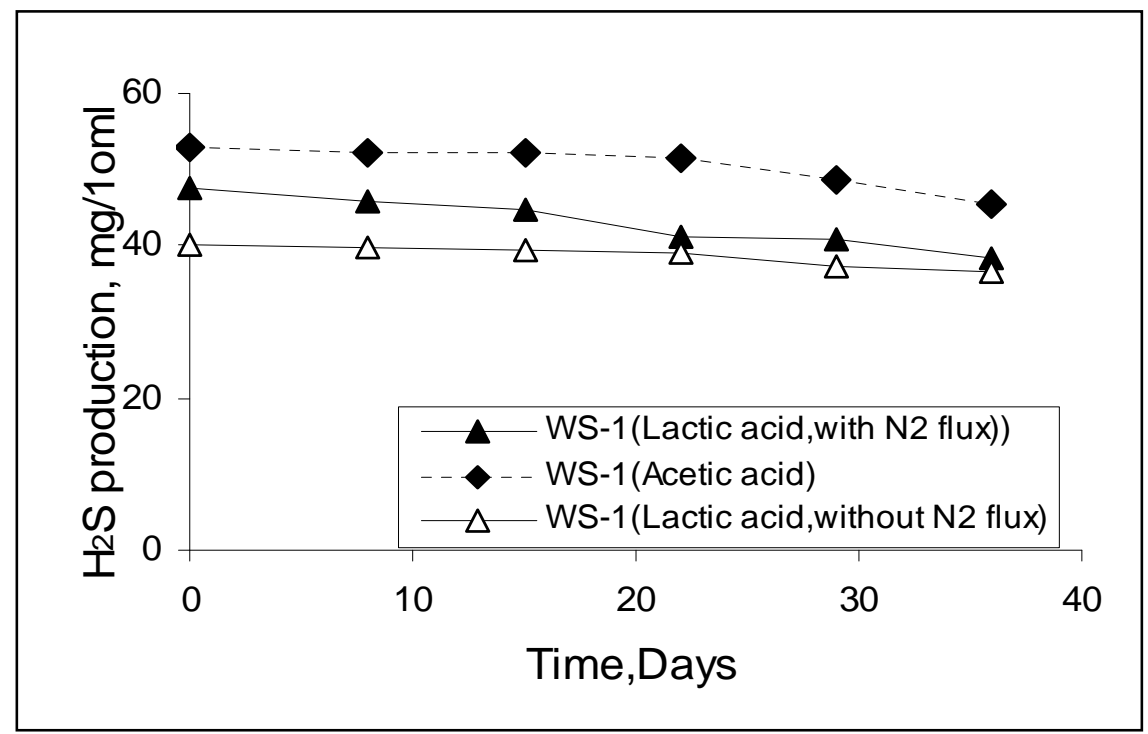

Figure 6. Effect of potassium nitrate on $\mathrm{H}_{2} \mathrm{~S}$ production by WS-1 strain in anaerobic basal mineral media with different conditions of nitrogen flux with lactic acid as substrate and with acetic acid as substrate

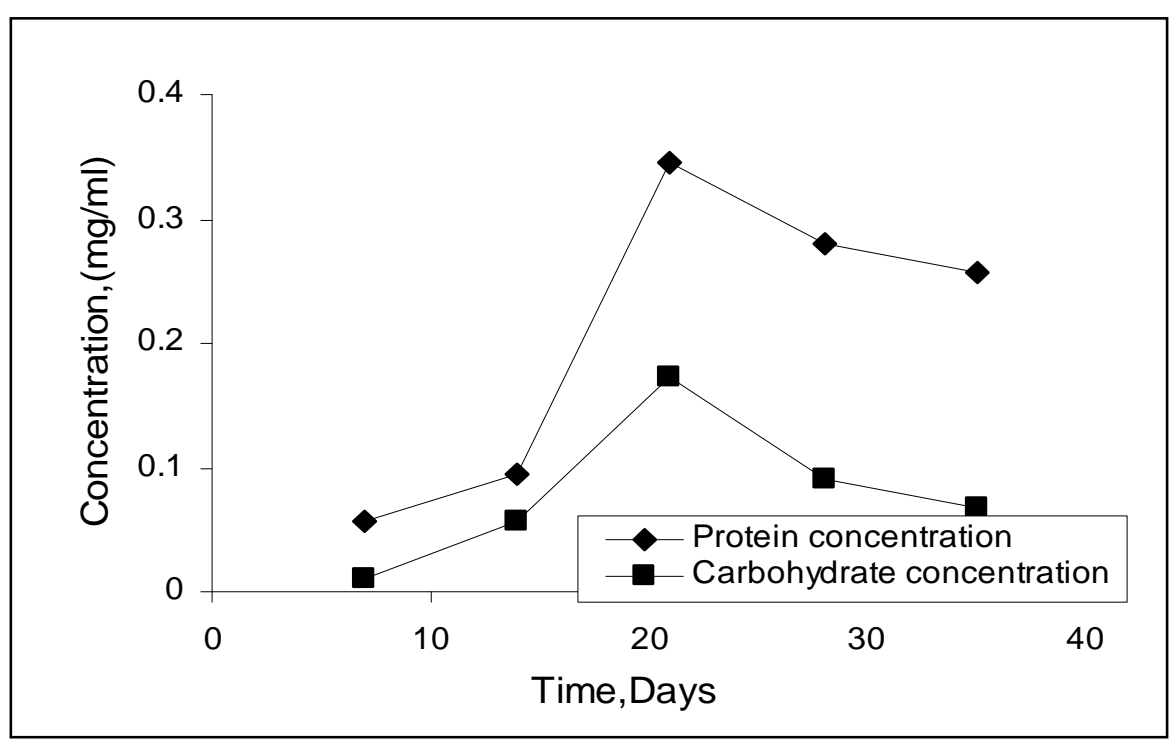

Figure 7. Protein and carbohydrate estimation of WS-1 strain by the digestion of biomass with $2 \mathrm{~N} \mathrm{NaOH}$ and direct heating and the absorbance was taken at 750nm and $620 \mathrm{~nm}$ respectively

\section{Effect of potassium nitrate salts on $\mathrm{H}_{2} \mathrm{~S}$ production}

Effect of potassium nitrate on the $\mathrm{H}_{2} \mathrm{~S}$ production was studied in comparison to sodium nitrate. $80 \mathrm{mM}$ of potassium nitrate was added with varying carbon sources. Potassium nitrate was added to two bottles with varying carbon sources (lactic acid and 
acetic acid) and also in both the bottles $\mathrm{N}_{2}$ gas was fluxed to maintain proper anaerobic condition but the control effect was less in comparison to sodium nitrate as shown in (Fig.6). From the study it was observed that the reduction in $\mathrm{H}_{2} \mathrm{~S}$ production was almost same for acetic acid and lactic acid substrate. Therefore it can be concluded from these results that carbon source has no effect on control conditions.

\section{Conclusion}

From the present study it was confirmed that SRB were indigenous to the sewage water. When the sample was incubated under anaerobic conditions, the microorganisms oxidized the supplied substrate and elemental sulfur present in the media that was disproportionate to hydrogen sulfide.

From the growth studies it can be concluded that lactic acid was preferred as a substrate in compared to that of acetate. It was observed that under sulfate reducing conditions, acetate was degraded more slowly than lactate, with no appreciable decrease after 2 weeks of incubation. This indicates the metabolic capacity of SRB to couple the degradation of a wide variety of substrates to poisonous hydrogen sulfide gas.

It was clear from the observations that the cultures that were fluxed with nitrogen show better growth and better $\mathrm{H}_{2} \mathrm{~S}$ production. The $\mathrm{H}_{2} \mathrm{~S}$ production was also substrate dependent and with lactic acid as a substrate better $\mathrm{H}_{2} \mathrm{~S}$ production was observed as compared with acetic acid as substrate.

The present study reveals that nitrate limited sulfate reduction and sulfide formation in cultures, regardless the variety of substrate used. It was observed that sodium nitrate was very effective in diminishing sulfate reduction whereas potassium nitrate has little controlling effect.

\section{REFERENCES}

[1] Allen, L.A. (1949): The effect of nitro-compounds and some other substances on production of hydrogen sulfide by sulfate reducing bacteria in sewage. - Proc. Soc. Appl. Bacteriol. 2: 26-38.

[2] Azabou, S., Mechichi, T., Patel Bharat, K.C., Sayadi S. (2007): Isolation and characterization of a mesophilic heavy-metals-tolerant sulfate-reducing bacterium Desulfomicrobium sp. from an enrichment culture using phosphogypsum as a sulfate source. - Journal of Hazardous Materials 140(1-2): 264-270.

[3] Busiman, C.J.N., Post, R., Ijspeert, P., Geraats, S., Lettinga, G. (1989): Biotechnological Process for Sulfide Removal with Sulfur Reclamation. - Acta Biotechnol 9: 271-283.

[4] Dang, P.N., Dang, T.C.H., Lai, T.H., Stan-Lotter, H. (1996): Desulfovibrio vietnamensis sp. nov., a halophilic sulfate-reducing bacterium from Vietnamese oil fields. - Anaerobe 2: 385-392.

[5] Ensley, B.D., Suflita, J.M. (1995): Metabolism of environmental contaminants by mixed and pure cultures of sulfate-reducing bacteria. - In: L. L. Barton (ed.). Sulfate-reducing bacteria. Plenum Press, New York, N.Y, p. 336

[6] Garcia, E.M., Siegert, I.G., Suarez, P. (1998): Toxicity Assays and Naphthalene Utilization by Natural Bacteria Selected in Marine Environments. - Bull. Environ Contam. Toxicol. 61: 370-377.

[7] Gardner, L.R., Stewart, P.S. (2002): Action of glutaraldehyde and nitrite against sulfatereducing bacterial biofilms. - J. Ind. Microbiol. Biotechnol. 29: 354-360. 
[8] Holt, J.G. (ed.)(1989) - In: Bergey 's Manual of Systematic Bacteriology -Williams and Wilkins,Baltimore.

[9] Jayaraman, A., Hallock, P.J., Carson, R.M., Lee, C.C., Mansfeld, F.B., Wood, T.K. (1999): Inhibiting sulfate-reducing bacteria in biofilms on steel with antimicrobial peptides generated in situ. - Appl. Microbiol. Biotechnol. 52: 267-275.

[10] Jenneman, G.E., Montgomery, A.D., McInerney, M.J. (1986): Effect of nitrate on biogenic sulfide production. - Appl. Environ. Microbiol. 51: 1205-1211.

[11] Nielsen, J.T., Liesack, W., Finster, K. (1999): Desulfovibrio zosterae sp. Nov.,a new sulfate reducer isolated from surface-sterilized roots of the seagrass Zostera marina. - Int. J. Syst.Bacteriol. 49(2): 859-865.

[12] Postgate, J.R. (1984): The Sulphate Reducing Bacteria. - In: 2nd ed., Cambridge University Press,Cambridge.

[13] Rao, T.S., Sairam, T.N., Viswanathan, B., Nair, K.V.K. (2000): Carbon steel corrosion by iron oxidising and sulphate reducing bacteria in a freshwater cooling system. - Corros. Sci. 42(8): 1417-1431.

[14] Vogel, A.I. (1961). - In: A Text Book of Inorganic Analysis, Longmans.

[15] Zhang, X., Young, L.Y. (1997): Carboxylation as an initial reaction in the anaerobic metabolism of naphthalene and phenanthrene by sulfidogenic consortia. - Appl. Environ. Microbiol. 63: 4759-4764. 